\title{
Análise da Retenção Hídrica em Telhados Verdes a Partir da Eficiência do Coeficiente de Escoamento
}

\author{
Alfredo Akira Ohnuma Jr ${ }^{1}$, Paulino de Almeida Neto ${ }^{2}$, Eduardo Mario Mendiondo ${ }^{2}$ \\ akira@uerj.br; paulino.an@gmail.com,emm@sc.usp.br,
}

Recebido: 23/10/11 - revisado: 20/04/12 - aceito: 03/12/13

\begin{abstract}
RESUMO
Este trabalho apresenta uma análise comparativa de reservação aplicada em telhados verdes. A proposta de inclusão em áreas urbanas teve como referência uma avaliação quantitativa do escoamento superficial gerado pela água da chuva sobre o telhado verde através do monitoramento de até 65 eventos distribuídos entre os meses de junho de 2004 e julho de 2005 - telhado verde protótipo A - e entre setembro de 2006 e março de 2007 - telhado verde protótipo B. A metodologia de cálculo e da estimativa de reservação de água pelo telhado verde considerou como hipótese evapotranspiração nula, devido a velocidade do escoamento para análises de pequenas escalas e intervalo do evento inferior a 1 hora. Os equipamentos utilizados compreendem: duas estações meteorológicas, um linígrafo manual e dois linígrafos automáticos com funções respectivamente para medir as precipitações dos eventos e registrar o nível de água a partir de um sensor tipo transdutor de pressão, sensor de temperatura, bateria de longa duração e coletor de dados. Os resultados indicam uma eficiência de até $56 \%$ no armazenamento obtido pelo telhado verde em comparação com um telhado do tipo convencional, tendo como característica a capacidade de retardar o escoamento. As recomendações para trabalhos futuros incluem: simulações do telhado verde em áreas maiores, com diferentes inclinações e análise de experimento com aplicaşão para o aproveitamento da água da chuva proveniente da cobertura verde.
\end{abstract}

Palavras-chave: telhado verde, reservação, monitoramento hidrológico, eficiência.

\section{INTRODUÇÃO}

Em todo o país a urbanização aliada ao inexpressível planejamento ambiental na construção de novos loteamentos e periferias tem acarretado diversos sinistros, como: as enchentes observadas em épocas de chuva, o aumento da temperatura em escala mesoclimática, a ocorrência de ilhas de calor urbano, o aumento do efeito estufa e a falta de água em grandes cidades. A preocupação com os aspectos ambientais e a sustentabilidade socioambiental sugerem o desenvolvimento de novas tecnologias de construção de baixo impacto ambiental.

A coberturas ou telhados verdes datam milhares de anos. Historicamente, as estruturas mais famosas são citadas nos Jardins Suspensos da Babilônia, considerados uma das sete maravilhas do

\footnotetext{
1 - Departamento de Engenharia Sanitária e Meio Ambiente Faculdade de Engenharia/UERJ

2 - Departamento de Hidráulica e Saneamento/Escola de Engenharia de São Carlos/USP
}

mundo. Construídas por volta de 500 anos a.C., os telhados estão sobrepostos em feixes de pedra com camadas de lingüetas e de piche grosso, compostos por camadas de solo, plantas e árvores.

As mais antigas coberturas verdes conhecidas na América do Norte foram instaladas nos anos de 1930 no Rockefeller Center, em Nova York nos Estados Unidos. Segundo Almeida Neto (2005), estes jardins nas coberturas continuam a florescer hoje após quase 70 anos de serviço.

Na Europa, após décadas de prática, os alemães melhoraram a técnica do telhado transformando-a em uma fina obra de arte. Cerca de $10 \%$ dos telhados alemães são constituídos de vegetação. Entre 1989 e 1999, conforme PennState (2008), as companhias alemãs do setor de coberturas instalaram mais de 32,5 milhões de $\mathrm{m}^{2}$ de telhados verdes $\mathrm{e}$ esse valor vem aumentando. Entre 1989 e 2002 foram subsidiados como forma de incentivo mais de 5 milhões de euros para a construção de mais de 268 mil metros quadrados de telhados verdes, na cidade de Linz na Áustria (LINZ, 2002).

A presença da cobertura vegetal em telhados contribui para a redução do volume de água escoada superficialmente para áreas de drenagem. 
Além disso, os telhados verdes atuam como agentes "filtradores", quando o material sólido em suspensão advindo com a água da chuva é eficientemente removido pelas gramíneas. A qualidade da água que emerge do telhado verde, portanto costuma ser superior em relação à água incidente, destacando o potencial do aproveitamento de água da chuva. Kolb (2003) intensificou o estudo sobre os telhados verdes com base nos resultados realizados na cidade de Veitshöchheim, na Alemanha, comprovando que essas estruturas verdes são capazes de reduzir significativamente a demanda por refrigeração, quando comparados com os telhados convencionais sem vegetação, com potencial de redução da amplitude térmica de 60 a $90 \%$.

$\mathrm{O}$ estudo tem como objetivo analisar comparativa e quantitativamente o escoamento superficial gerado por 02 (dois) telhados verdes (protótipo A e protótipo B) com análise da eficiência de reservação obtida pelo coeficiente de escoamento. Foram analisadas inclusive as variáveis de precipitação $(\mathrm{P})$, escoamento $\left(\mathrm{P}_{\mathrm{ef}}\right)$, infiltração $(\mathrm{F})$ e perdas iniciais $\left(I_{\mathrm{a}}\right)$. O estudo foi realizado na EESC - Universidade de São Paulo (USP).

\section{COMPOSIÇÃO DOS TELHADOS VERDES}

A estrutura do telhado verde tem em sua concepção tradicional o retardamento do escoamento superficial das águas pluviais quando comparados com uma cobertura tradicional (telha cerâmica ou de fibrocimento). Observa-se na Figura 1 o processo de infiltração nos dois tipos de superfície. Na cobertura verde, a parte da água precipitada é infiltrada na superfície e outra parte retorna ao sistema pelo processo de evaporação. Uma pequena parte é escoada ao sistema de esgoto e tratamento de águas pluviais. Na cobertura tradicional, a maior quantidade de água escorre diretamente para o sistema público de águas pluviais, ocasionando assim, um super fluxo que muitas vezes gera as famosas inundações urbanas.

Os resultados da comparação entre uma cobertura convencional e um teto verde são analisados por avaliação experimental (monitoramento hidrológico) a partir da aquisição e armazenamento de dados pluviométricos (estação meteorológica) e da geração do escoamento (linígrafos).

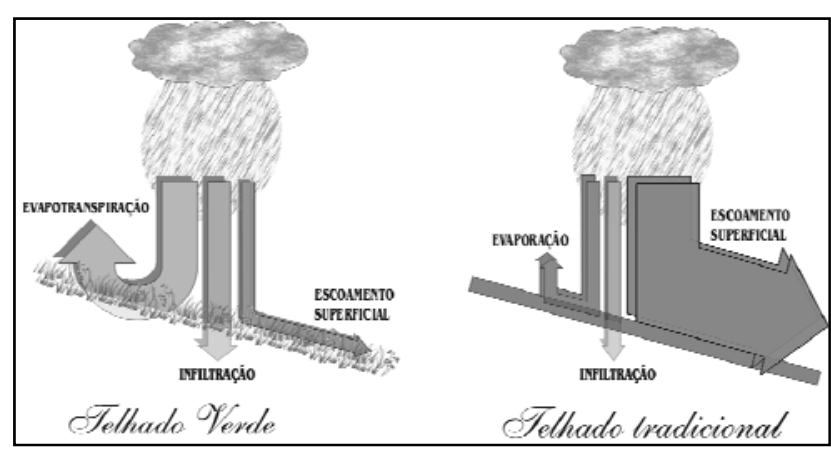

Figura 1 - Comparação de escoamento de uma cobertura verde com uma cobertura tradicional.

\section{METODOLOGIA}

\section{Características dos telhados verdes}

O estudo teve como referência duas áreas distintas, em local com baixo potencial de sombreamento. O experimento A da Figura 2 foi construído em um protótipo pré-existente com dimensões da laje de $2,8 \times 4,2 \mathrm{~m}$ ou $11,8 \mathrm{~m}^{2}$. Foram instaladas duas saídas para o escoamento de águas pluviais, sendo a coleta realizada para: análise do estudo hidrológico e verificação da redução do escoamento superficial (runoff). A Figura 3 apresenta as diversas camadas do substrato para a composição do telhado verde.

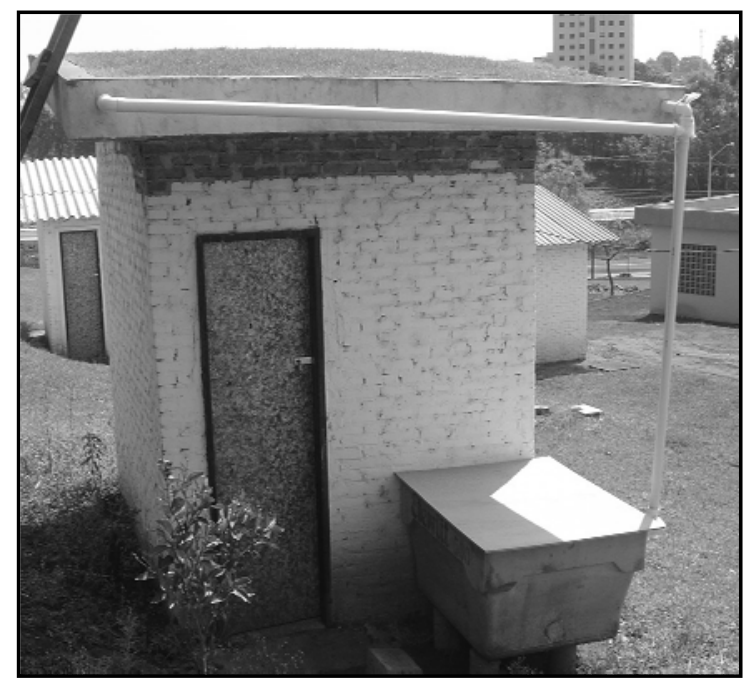

Figura 2 - Telhado verde (Protótipo A), com reservatório de armazenamento (Área $a_{A}=11,8 m^{2}$ ). 


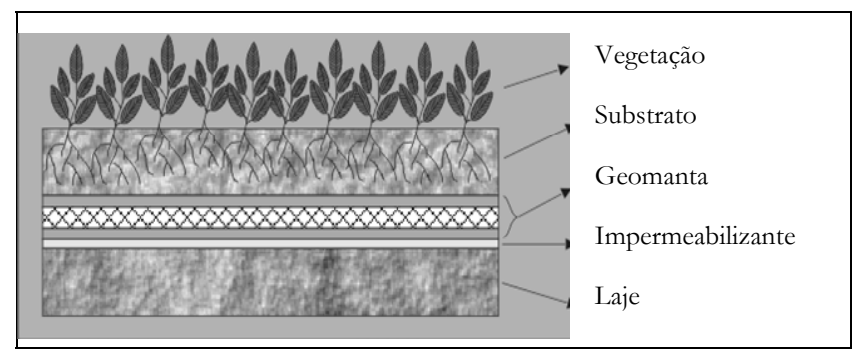

Figura 3 - Camadas de substratos do telhado verde.

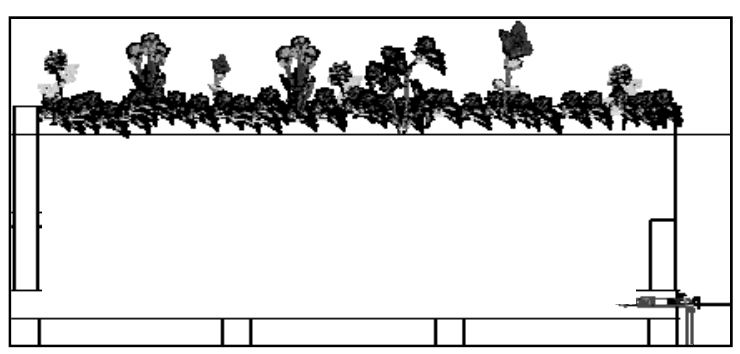

Figura 4 - Projeção lateral da estrutura do telhado verde (Protótipo B).

O telhado verde do protótipo B (Figuras 4 e 5) foi executado com laje pré-moldada do tipo $\beta 8$, dimensões de 1,6 x 5,9m e declividade de $3 \%$. Para o escoamento na superfície da cobertura construiu-se uma platibanda com $15 \mathrm{~cm}$ de altura, com substrato orgânico e plantio de culturas herbáceas com vegetação rasteira. $\mathrm{O}$ uso predominante deste tipo de vegetação, para este estudo, menospreza os efeitos do escoamento para simulação numérica, uma vez que pode interferir nos resultados finais do armazenamento pelo solo.

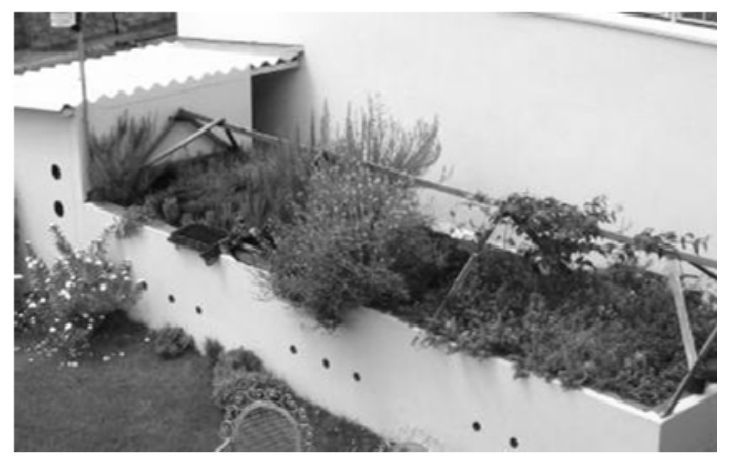

Figura 5 - Telhado verde (Protótipo B) $\left(\right.$ Área $\left._{\mathrm{B}}=\mathbf{9 , 4 \mathbf { m } ^ { 2 }}\right)$.
Toda estrutura para telhados verdes, segundo Kirby (2005), deve observar com acuidade a necessidade de instalação de uma membrana de impermeabilização a fim de garantir uma melhor estabilidade nas áreas molháveis e fornecer uma aderência completa ao substrato.

\section{Monitoramento de nível}

Utilizou-se para o experimento A um equipamento de medição de nível e uma estação meteorológica contendo: data-logger, módulo de armazenamento, pluviômetro, sensor de radiação solar, sensor de raios ultravioleta, temperatura, umidade relativa do ar, pressão barométrica, sensor de direção e velocidade do vento. Para a medição do nível de água no reservatorio utilizou-se um linígrafo de bóia convencional, observado na Figura 6, designado para registrar continuamente as medições de níveis baseados nas oscilações de um flutuador.

$\mathrm{Na}$ área de estudo do experimento $\mathrm{B}$, utilizou-se outra estação meteorológica de mesmo modelo e características que a anterior, no entanto instalada na sua respectiva área de contribuição, localizada em suporte acima do telhado verde, conforme Figura 7.

Devido à velocidade do escoamento superficial no lote ser alta e da escala espacial ser pequena, reduzindo o tempo de concentração da área em estudo, foi realizada na área do telhado verde (B) a sincronização de tempo de todos os equipamentos instalados, inclusive da Estação Meteorológica. Assim, foram feitos ajustes para a coleta das informações em tempo real conforme discretização e monitoramento de dados em total sincronia, ou seja, com equipamentos calibrados para o mesmo instante de hora, minuto e segundo.

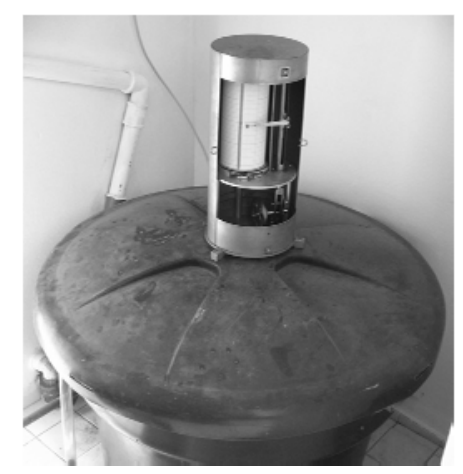

Figura 6 - Linígrafos de bóia convencional e automático 


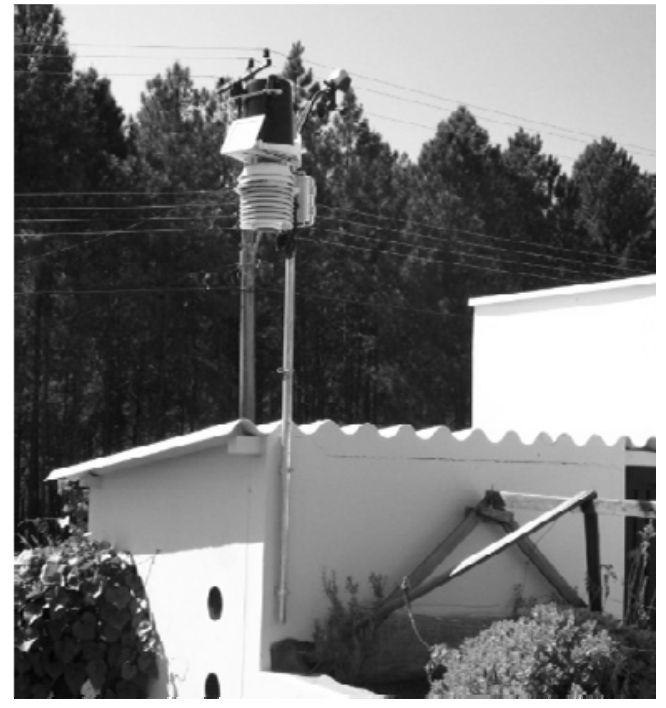

Figura 7 - Estação Meteorológica instalada sobre área do telhado verde (Protótipo B).

\section{Volume de água escoada pelo telhado verde Protótipo A}

Para se determinar o volume de água escoado para a caixa d’água e em seguida transformá-lo no equivalente em $\mathrm{mm}$ de chuva, para comparação gráfica, foi efetuado um estudo geométrico da caixa d’água e do telhado. Uma análise com os linigramas obtidos pelo linígrafo de bóia e a caixa d’água mostrou a seguinte relação:

a) as duas primeiras linhas verticais do linigrama, cujo intervalo de tempo equivale a 2 horas, corresponderam a 75 litros de água;

b) o telhado com $11,8 \mathrm{~m}^{2}$ de área gerou uma lamina de $3,2 \mathrm{~mm}$;

c) as próximas seis linhas do linigrama corresponderam a 275 litros de água, resultando uma média de aproximadamente $4 \mathrm{~mm}$ para cada nova medida (Figura 8).

Este gráfico em linigrama avalia as condições do escoamento pelo telhado verde a partir do volume reservado e infere capacidade de retenção hídrica que varia conforme a umidade do solo. Após determinado intervalo de tempo, observa-se que há limite no volume de retenção observado pelo telhado verde.

Os equipamentos utilizados para medir os níveis do escoamento pelo telhado verde fazem parte do LAEG-EESC-USP (Laboratório Ambiental para Ensino de Graduação, Escola de Engenharia de São Carlos, Universidade de São Paulo).

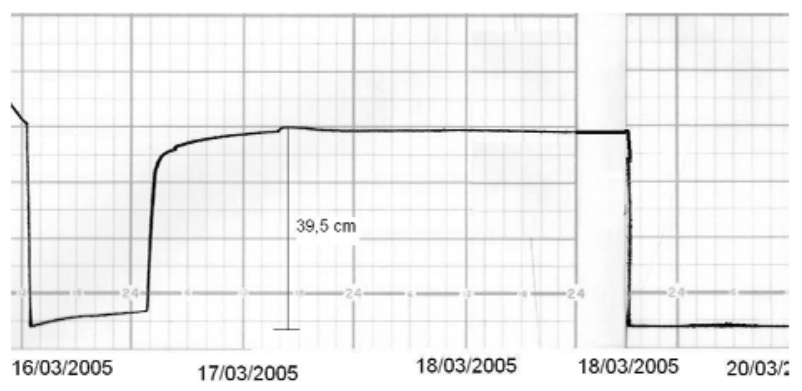

Figura 8 - Linigrama do evento de 16 a 21/03/2005.

\section{Volume de água escoada pelo telhado verde Protótipo B}

O escoamento percorre o dreno de saída em direção ao reservatório com capacidade para 320 litros. Para fins de manutenção e limpeza do sistema foram instalados: extravasor e tubo de queda para esgotamento da caixa a partir de um registro de esfera.

Com uma área interna de escoamento de $9,4 \mathrm{~m}^{2}$, a capacidade de reservação da lâmina máxima equivalente foi calculada pela Equação (1).

$$
E(\mathrm{~mm})=\frac{\Delta V}{A}=34,04 \mathrm{~mm}
$$

Sendo E a lâmina equivalente em $\mathrm{mm} ; \Delta V$ o volume de reservação total do reservatório $\mathrm{em}^{3}$ e $A$ área total do telhado verde em $\mathrm{m}^{2}$.

A condição máxima de reservação d'água proveniente do telhado verde foi estimada, portanto para uma precipitação de até $34 \mathrm{~mm}$. Este foi o valor máximo considerado a reservar para o escoamento gerado pelo teto verde, desconsiderando tanto os acúmulos efetuados para o cálculo em série, quanto para a altura de lâmina d’água off-set necessária para o início das medições.

No entanto, segundo Ohnuma Jr. (2008), a capacidade de armazenamento $\mathrm{S}$ sobre o telhado verde pode variar em função da intensidade da chuva e dos intervalos inter-eventos, ou seja, da intensidade da precipitação antecedente. $\mathrm{O}$ valor considerado para a obtenção do armazenamento $\mathrm{S}$ em $\mathrm{mm}$ pode ser calculado a partir da altura h do telhado verde e da porosidade $\emptyset_{\text {s }}$ do solo utilizado no plantio, conforme Equação 2. 
$S=h \times \phi_{\mathrm{s}} \times 1000=80 \mathrm{~mm}$

Sendo $\mathrm{S}=$ armazenamento máximo acumulado sobre o telhado verde em $\mathrm{mm} ; \mathrm{h}=$ altura da platibanda sobre o telhado verde $\mathrm{em} \mathrm{mm}$ e $\emptyset_{\mathrm{s}}=$ porosidade do solo utilizado no plantio.

Segundo Kochhann et al (1999) os resultados de análises físicas no solo indicam porosidade em sua estrutura molecular que variam entre $48 \mathrm{e}$ $58 \%$ para profundidades entre 0 e $15 \mathrm{~cm}$ de solo. Considerando uma porosidade $\emptyset$ s do solo utilizado no plantio de $53 \%$ e uma altura h da platibanda de $150 \mathrm{~mm}$, obtém-se um armazenamento máximo de até $80 \mathrm{~mm}$, correspondente ao limite de precipitação acumulada no telhado verde e sem considerar o extravasamento na saída dos condutores.

\section{Método SCS}

Durante o período de junho de 2004 a julho de 2005 foram coletados dados de chuva e escoamento de 13 eventos, válidos para o Telhado Verde (A). Para esses dados, aplicou-se a curva de tendência do telhado verde considerando a precipitação no eixo das abscissas e o escoamento no eixo das ordenadas. Inseriu-se no mesmo gráfico uma reta de quarenta e cinco graus representando a precipitação acumulada. Ao subtrair a curva de tendência pela reta da precipitação acumulada obteve-se a curva acumulada da infiltração mais as perdas iniciais ( $\mathrm{F}+$ Ia), sendo esta última obtida através da curva de tendência exatamente no instante em que se inicia o escoamento.

Kohler e Richards (1962, apud TUCCI 2001) verificaram que, em média, as perdas iniciais representavam $20 \%$ (vinte por cento) da capacidade máxima de armazenamento do solo como $\mathrm{S}=\mathrm{S}^{*}$-Ia, ou seja, Ia $=0,2$. S.. Para determinar a capacidade máxima da camada superior do solo $\mathrm{S}$, os autores relacionaram esse parâmetro da bacia com um fator CN pela expressão (3) conhecida como aquela que retrata as condições de cobertura e uso do solo, variando desde uma cobertura muito impermeável (limite inferior) até uma cobertura completamente permeável (limite superior).

$\mathrm{S}=(25400 / \mathrm{CN})-254$

\section{Balanço Hídrico}

O comportamento hidrológico proporcionado pelo telhado verde, após a ocorrência de uma seqüência de precipitações, indica que, após o início das chuvas, existe um intervalo de tempo para o início do escoamento, dependendo das condições de umidade do solo. Conforme Ohnuma Jr (2008), este intervalo deve-se ao armazenamento inicial, às perdas iniciais por interceptação e depressões sobre o telhado, além do próprio tempo de retardo de resposta da superfície devido ao deslocamento até o início do escoamento.

A Equação (4) expressa a condição do balanço hídrico para eventos considerados pequenos ou de curto prazo, tendo como hipótese a ETR=0. Nesse caso, assume-se, conforme Beven (1986), que os processos hidrológicos ou caminhos preferenciais da água no escoamento subsuperficial sobre o telhado verde tendem a ocorrer a partir de hipóteses que consideram apenas a verticalidade da infiltração na função dos parâmetros de entrada e saída.

Retenção $=P_{a c}-L_{e q . a c}$

Sendo Retenção = lâmina retida pelo solo ou devido às perdas iniciais; $\mathrm{P}_{\mathrm{ac}}=$ precipitação acumulada do evento e $\mathrm{L}_{\text {eq.ac }}=$ lâmina equivalente do escoamento gerada pelo telhado verde.

Os eventos selecionados de curto prazo representam as precipitações e lâminas equivalentes, ou precipitações efetivas, geradas em períodos menores que um dia. A seleção leva em consideração a análise de eventos significativos e característicos com tempo de resposta do escoamento instantes após o início da precipitação.

\section{Método de cálculo da eficiência hídrica}

A eficiência da retenção hídrica pelo solo sobre o telhado verde em relação a um telhado convencional, considerando este com geração de $90 \%$ de precipitação efetiva em relação a precipitação total, pode ser estimada a partir da Equação 5.

$$
E_{r} T V(\%)=100 .\left(1-\frac{\beta}{\theta}\right)
$$

Sendo, $\mathrm{E}_{\mathrm{r}} \mathrm{TV}=$ eficiência na retenção hídrica do telhado verde; $\theta$ = ângulo correspondente ao $C e$ (coeficiente de escoamento) do telhado convencional e $\beta=$ ângulo correspondente ao $C e$ do telhado verde. 


\section{RESULTADOS}

Principais eventos ocorridos para as áreas verdes A e B entre junho de 2004 e março de 2007.

Os gráficos das Figuras 9 a 14 ilustram o comportamento da precipitação observada em função do escoamento para o telhado verde (A).

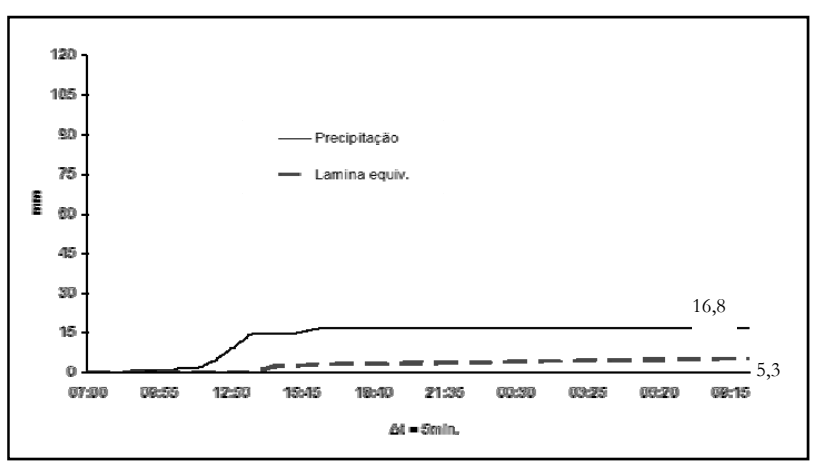

Figura 9 - Evento de 12 de junho de 2004 (Protótipo A).

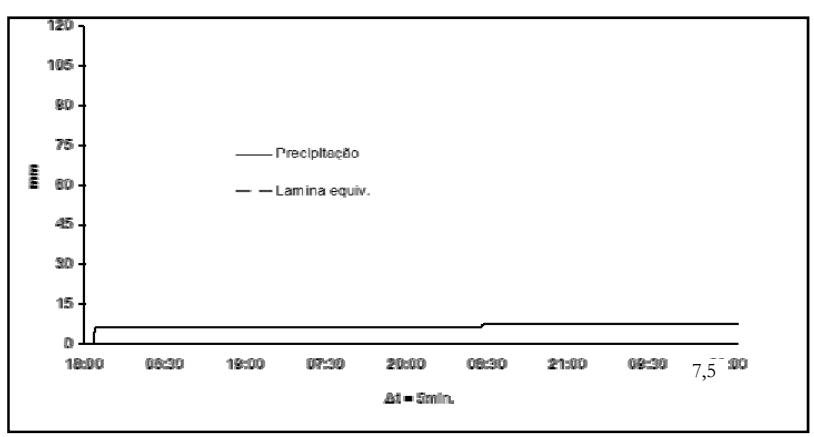

Figura 10 - Evento entre 14 e 16 de junho de 2004. (Protótipo A)

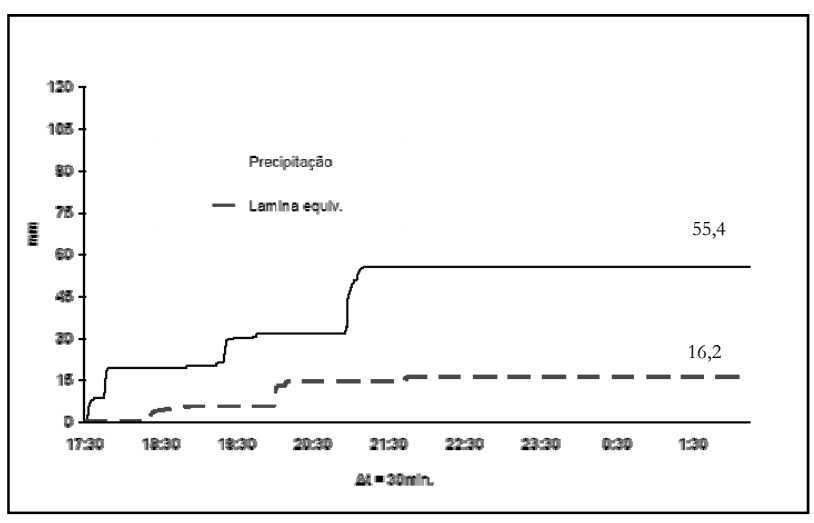

Figura 11 - Evento entre 19 e 20 de outubro de 2004. (Protótipo A)

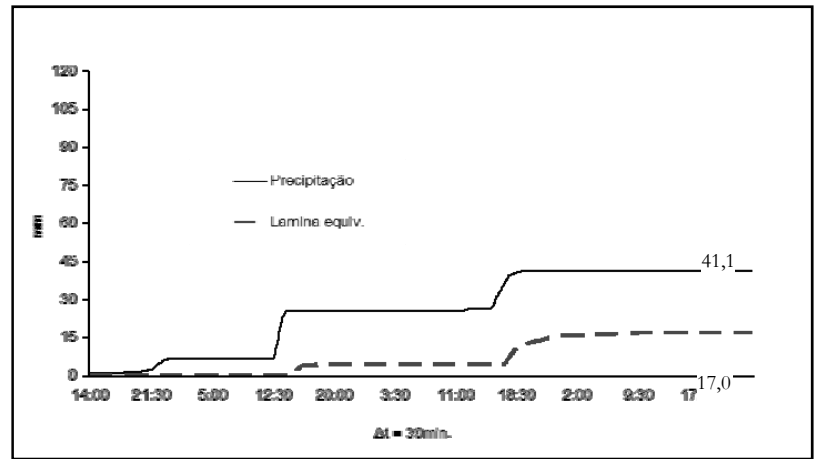

Figura 12 - Evento entre 25 e 29 de fevereiro de 2005 (Protótipo A).

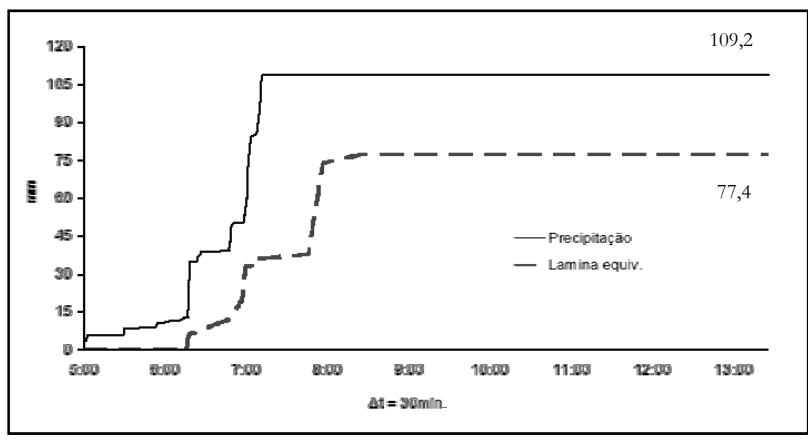

Figura 13 - Evento de 15 de março de 2005 (Protótipo A).

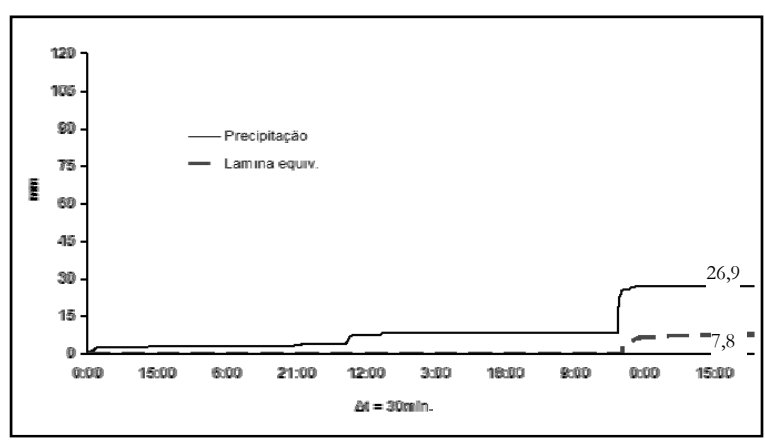

Figura 14 - Evento entre 24 e 25 de março de 2005 (Protótipo A).

Eventos independentes descritos neste artigo referem-se aos eventos com intervalos sem precipitação maior do que 30 minutos. Determinados eventos ocorrem na madrugada e por isso são descritos entre um dia e outro. Outros eventos possuem intervalo de discretização de 30 minutos com dados coletados maiores do que um dia.

Os eventos relacionados para o telhado verde (Protótipo A) indicam tempo de resposta ou de retenção da água no solo variável entre 01 hora e 07 
horas. Os valores representam oportunidades de análise nas condições de umidade antecedente do solo, sendo condição prioritária para avaliação do potencial de escoamento superficial no telhado verde.

Ao analisar a relação entre o escoamento e o valor precipitado, obtém-se coeficientes de até 0,71 conforme evento entre 15 e 22/03/2005. A média do coeficiente de escoamento para os eventos analisados foi de 0,40 .

A Figuras 15 a 20 correspondem aos eventos analisados pelo telhado verde do protótipo B. As Figuras 15 a 20 diferenciam das Figuras 9 a 14 pela representação nos gráficos indicados com a parcela da capacidade de retenção do escoamento.

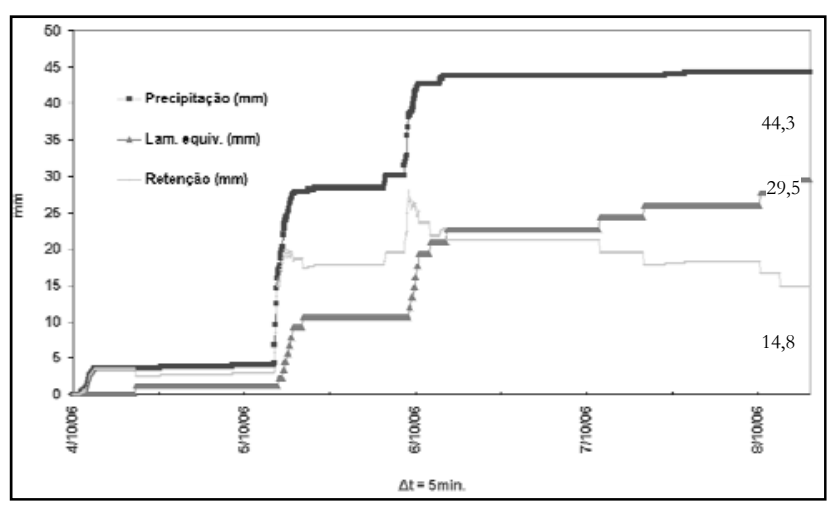

Figura 15 - Evento entre 04 e 06 de outubro de 2006 (Protótipo B).

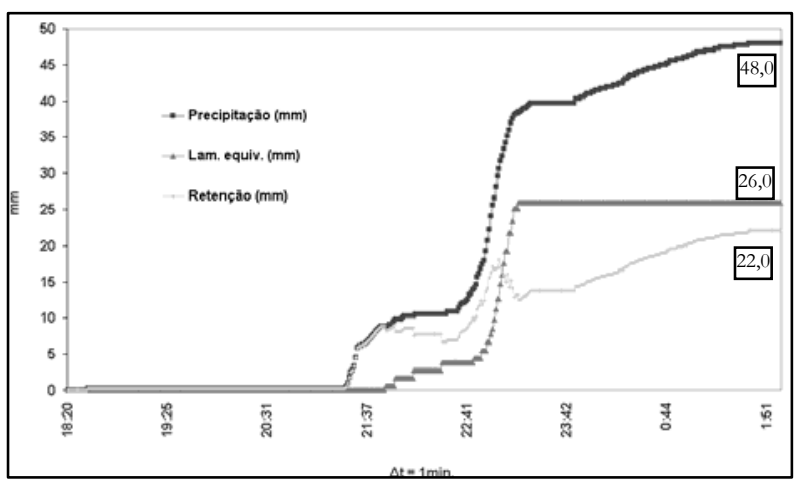

Figura 16 - Evento entre 06 e 07 de dezembro de 2006 (Protótipo B).

Com a precipitação total observada de aproximadamente $45 \mathrm{~mm}$, o evento em 20/12/2006 obteve uma lâmina de escoamento equivalente a 31 mm. No entanto, ao discretizar esse evento total em dois eventos independentes (determinados pela precipitação), inferem-se lâminas equivalentes de 8 $\mathrm{mm}$ e $16 \mathrm{~mm}(24-8 \mathrm{~mm})$. A diferença entre as lâminas totais devem-se às perdas iniciais e ao armazenamento inicial pelo solo.

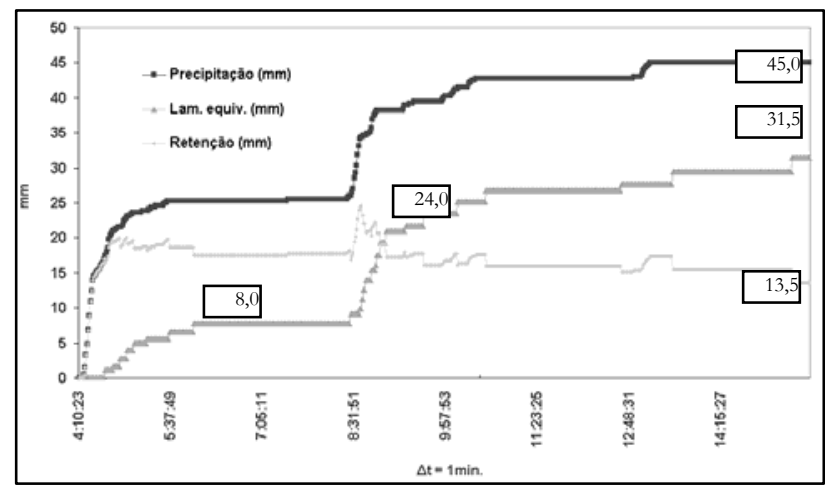

Figura 17 - Evento em 20 de dezembro de 2006 (Protótipo B).

O evento de 18/01/2007 obteve intensidade pluviométrica de $6 \mathrm{~mm} / \mathrm{h}$ com taxa de $52 \%$ de escoamento do valor precipitado. Isto é, provavelmente, conseqüência do relativamente alto, índice de precipitação antecedente nos últimos cinco dias que foi próximo de $50 \mathrm{~mm}$. Conseqüentemente, o período de permanência ou de retenção da água no solo foi considerado curto com tempo de 15 minutos.

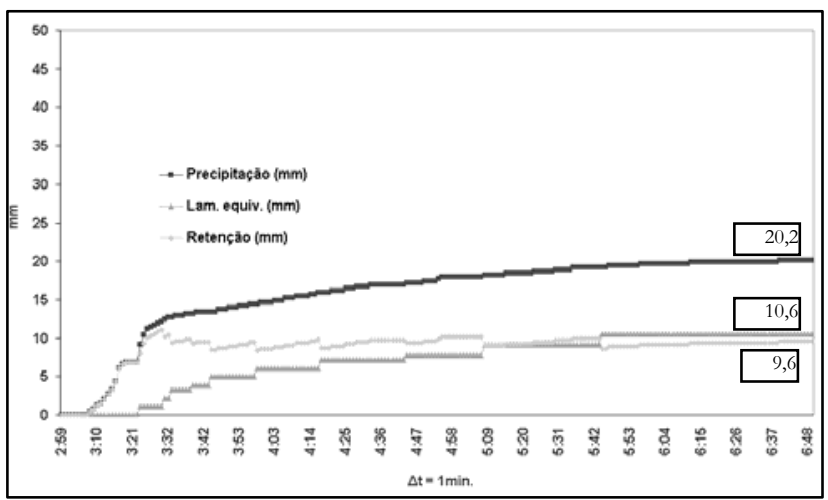

Figura 18 - Evento em 18 de janeiro de 2007 (Protótipo B).

Os reflexos do meio saturado no evento de 18/03/2007 demonstram que o fluxo de água através do solo foi alto, considerando os níveis de lâminas atingidos durante a tormenta. $\mathrm{O}$ incremento da precipitação após a saturação, indica um deslocamento crescente dos volumes de água retidos no 
solo. Este comportamento ocorre também devido à declividade do telhado verde e à coleta do volume excedente pelos seus respectivos condutores de saída.

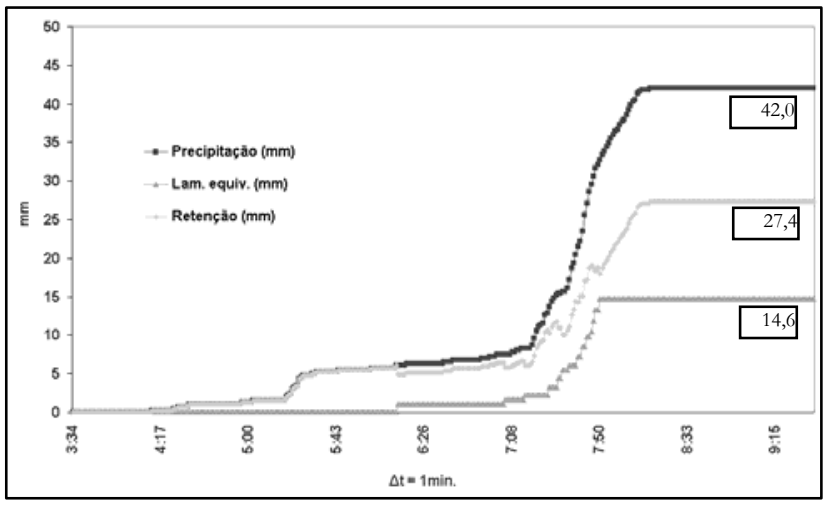

Figura 19 - Evento em 26 de janeiro de 2006 (Protótipo B).

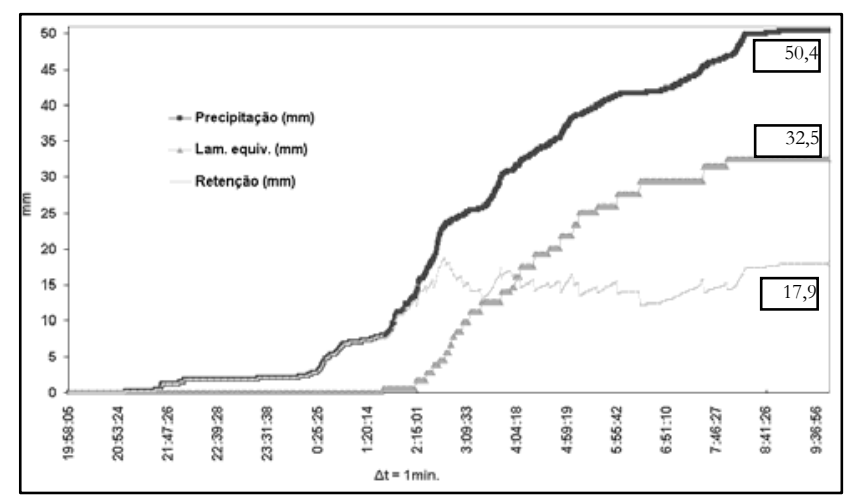

Figura 20 - Evento em 18 de março de 2007 (Protótipo B).

O balanço hídrico sobre o telhado verde requer uma análise da dinâmica dos processos hidrológicos envolvidos. Sua constituição, embora construtivamente simples, requer uma análise hidrológica dos diferentes mecanismos que envolvem o seu ambiente como: as camadas superficiais do solo capazes de produzir o escoamento e a sua saturação, bem como a sua capacidade de armazenamento; os índices de precipitação antecedente, intensidade pluviométrica; entre outros.

\section{Curva de tendência e análise da eficiência hídrica}

Os eventos obtidos durante o período de junho de 2004 a março de 2007 para a área A e B originaram a curva de tendência de ambos telhados verde. $\mathrm{O}$ resultado segue na Tabela 1 . O coeficiente de escoamento é dado por Ce, o intervalo de tempo $\Delta \mathrm{t}$ (em dias) representa o tempo de resposta do início do escoamento e TS (em dias) o intervalo de tempo seco antecedente ao início do evento.

Tabela 1 - Eventos observados $\left(\mathrm{P}_{\text {total }}\right)$ e lâminas de escoamento $\left(\mathrm{P}_{\text {efet }}\right)$ do telhado verde $(\mathrm{A})$ e $(\mathrm{B})$.

\begin{tabular}{|l|l|l|l|l|l|l|}
\hline $\mathbf{N}$ & Data & $\mathbf{P}_{\text {total }}$ & $\mathbf{P}_{\text {efet }}$ & $\mathbf{C e}$ & $\begin{array}{l}\Delta \mathbf{t} \\
(\mathbf{d})\end{array}$ & $\mathbf{T S}(\mathbf{d})$ \\
\hline 1 & 12.06 .04 & 16,8 & 5,4 & 0,32 & 1,90 & 1,48 \\
\hline 2 & 14.06 .04 & 7,5 & 0,0 & - & - & 1,91 \\
\hline 3 & 10.07 .04 & 11,6 & 0,0 & - & - & 1,78 \\
\hline 4 & 18.07 .04 & 35,4 & 23,9 & 0,68 & 0,20 & 0,15 \\
\hline 5 & 19.10 .04 & 55,4 & 16,2 & 0,29 & 2,09 & 1,64 \\
\hline 6 & 25.02 .05 & 36,2 & 21,8 & 0,60 & 0,26 & 0,54 \\
\hline 7 & 15.03 .05 & 109,2 & 77,4 & 0,71 & 0,24 & 0,42 \\
\hline 8 & 24.03 .05 & 26,9 & 7,8 & 0,29 & 2,15 & 1,67 \\
\hline 9 & 01.04 .05 & 42,2 & 10,4 & 0,25 & 2,18 & 1,76 \\
\hline 10 & 22.05 .05 & 66,6 & 30,3 & 0,45 & 1,06 & 1,17 \\
\hline 11 & 18.06 .05 & 11,4 & 0,0 & - & - & 1,45 \\
\hline 12 & 28.06 .05 & 12,7 & 0,0 & - & - & 1,67 \\
\hline 13 & 18.07 .05 & 6,4 & 0,0 & - & - & 1,65 \\
\hline 14 & 04.10 .06 & 44,3 & 29,5 & 0,67 & 0,28 & 0,55 \\
\hline 15 & 06.12 .06 & 48,0 & 26,0 & 0,54 & 1,02 & 1,11 \\
\hline 16 & 20.12 .06 & 45,0 & 31,5 & 0,70 & 0,22 & 0,36 \\
\hline 17 & 18.01 .07 & 20,2 & 10,6 & 0,52 & 0,95 & 0,99 \\
\hline 18 & 26.01 .07 & 42,0 & 27,4 & 0,65 & 0,25 & 0,41 \\
\hline 19 & 18.03 .07 & 50,4 & 32,5 & 0,64 & 0,24 & 0,33 \\
\hline & & & & & & \\
\hline
\end{tabular}

Os dados da tabela indicam que há uma estreita relação entre o coeficiente de escoamento (Ce) e os intervalos de tempo reposta e tempo seco. Há uma forte tendência para elevados valores do Ce quando tempo mais úmido, em detrimento do tempo de resposta do escoamento ser mais rápido. Valores menores de Ce são resultados de tempos mais secos e maior tempo de resposta para o início do escoamento ou dado pelo maior tempo de retenção.

A Figura 21 ilustra a curva de tendência a partir da análise dos 13 eventos acima, obtidos pelo linígrafo de bóia convencional. A precipitação total acumulada desses eventos foi de $445 \mathrm{~mm}$ com escoamento de $175 \mathrm{~mm}$.

O gráfico da Figura 22 adiante apresenta os dados observados para o telhado verde $\mathrm{B}$, compostos por mais de 50 eventos distribuídos em 6 meses de análises. A dispersão dos pontos analisados indica 
variabilidade no coeficiente de escoamento enquanto relação entre precipitação total e efetiva devido às variações de umidade antecedente do solo decorrente dos eventos precipitados.

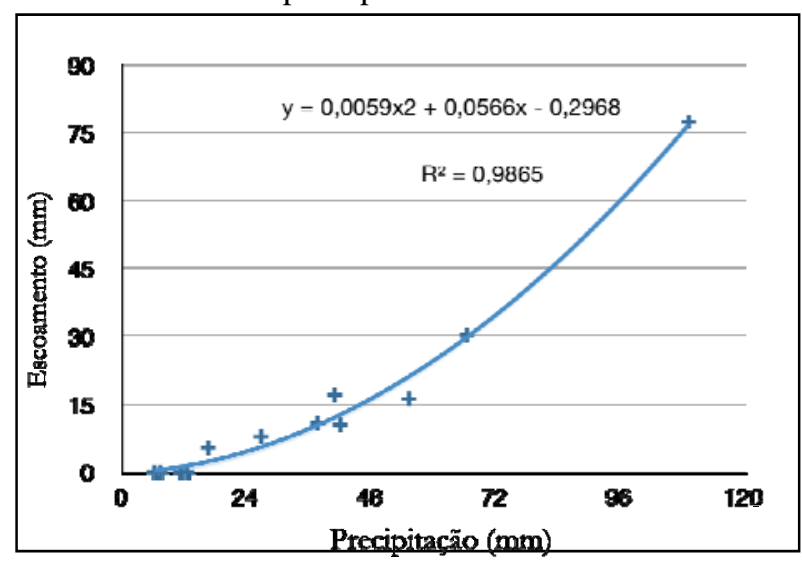

Figura 21 - Tendência dos eventos para o protótipo (A).

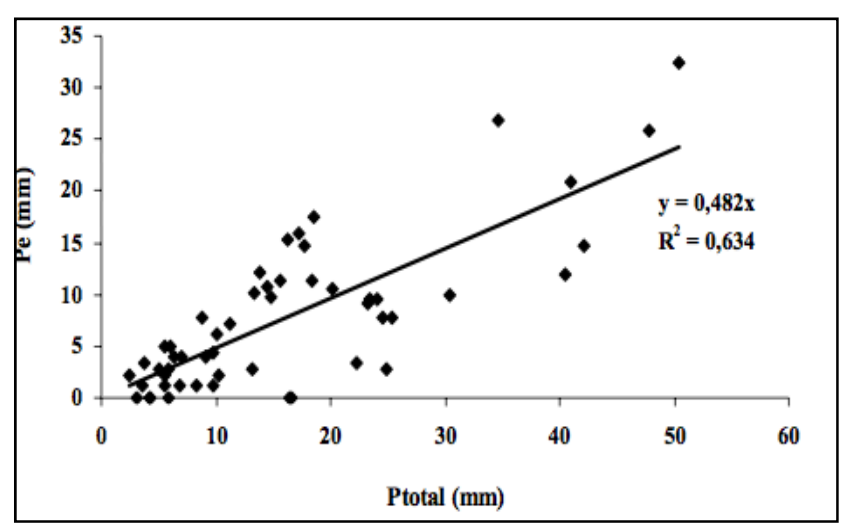

Figura 22 - Tendência dos eventos para o protótipo (B).

Devido os processos hidrológicos envolvidos no substrato do telhado verde serem dinâmicos, as características hidrológicas que geram o escoamento sobre o telhado verde devem ser avaliadas criteriosamente, pois são passíveis de interferências que podem comprometer os resultados de armazenamento. Deve-se levar em consideração, além das condições de umidade antecedente do solo, a intensidade pluviométrica no período e a porosidade do solo. Mesmo em baixos índices de precipitação, podem ocorrer elevadas taxas de escoamento superficial ou retenção da água pelo solo, devido às condições de saturação do solo.

A presença do telhado verde instalado no lote, com as suas devidas características acerca do local de implantação, contribuiu para a retenção do volume de escoamento sobre área específica do lote. Ao eliminar esta medida, os volumes retidos seriam rapidamente escoados para fora do lote. Como há uma movimentação lenta do escoamento interno sub-superficial sobre o telhado verde que produz uma determinada vazão de saída, a retenção gerada auxilia na distribuição dos volumes d'água retardando o escoamento para a microdrenagem.

A Figura 23 compara $\mathrm{P}_{\mathrm{TC} . S \mathrm{~S}}=$ precipitação efetiva no telhado convencional sem controle; $\mathrm{P}_{\mathrm{TV} . \mathrm{CC}}$ = precipitação efetiva no telhado verde com controle e $\mathrm{Pt}=$ precipitação total. $\mathrm{O}$ cálculo da eficiência na retenção hídrica expressa que o telhado verde é $56 \%$ mais eficiente na retenção hídrica em resposta ao telhado convencional, considerando este com $90 \%$ da precipitação efetiva em relação a precipitação total ou coeficiente de runnoff de 0,9 (WILKEN, 1978).

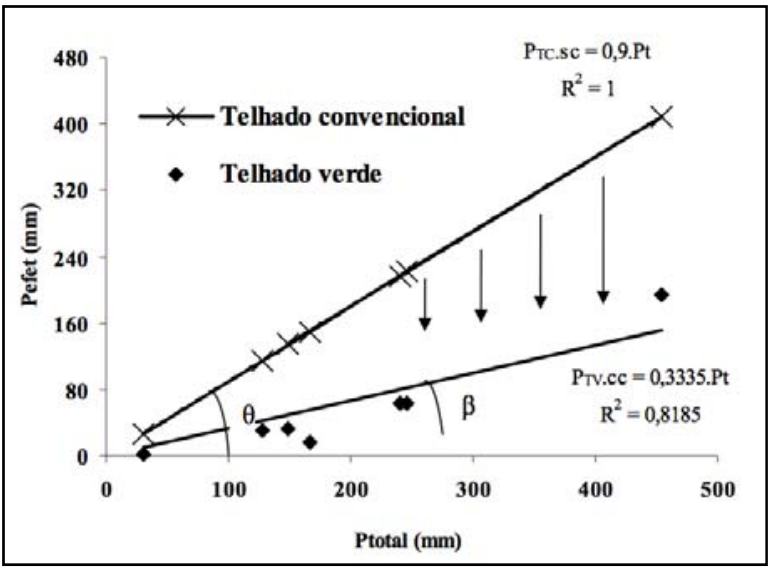

Figura 23 - Análise da eficiência da retenção hídrica pelo telhado verde $(B)$.

A retenção obtida no presente estudo corrobora resultados de Oliveira et al (2008) que observaram nas simulações das chuvas coincidentemente uma retenção de $56 \%$ do volume precipitado. Variações no coeficiente de runnoff entre 0,50 e 0,95 podem causar diferenças no comportamento da eficiência da retenção hídrica entre 30 e 57\% aproximadamente.

Considerando a referência de origem canadense FLL (2002) com resultado médio de retenção hídrica anual em torno de $55 \%$, tais dados revelam uma aproximação dos resultados encontrados neste trabalho, com estimativa superior a $50 \%$ de retenção, incluindo as perdas iniciais e a evapotranspiração no período selecionado de setembro de 2006 e março de 2007. Estudos obtidos por Köhler et al (2003) afirmam que cerca de $75 \%$ das chuvas preci- 
pitadas são capazes de ficar retidas no substrato vegetal das coberturas verdes.

\section{Cálculo do $C N$}

Para estimar o CN sobre o telhado verde utilizou-se a expressão (3) apresentada anteriormente. Os valores obtidos de $I a$ (perdas iniciais), $S$ (armazenamento) e $C N$ (curva-número) das áreas protótipos A e B estão representados na Tabela 2.

Tabela 2 - Estimativa de $C N$ do telhado verde para os protótipos A e B

\begin{tabular}{llll}
\hline Telhado Verde & Ia & S & CN \\
\hline Protótipo A & 10 & 50 & 84 \\
\hline Protótipo B & 16 & 80 & 76 \\
\hline
\end{tabular}

O resultado apresenta uma variabilidade nos valores de $C N$ calculados pelo método SCS nos experimentos A e B. Devido às condições do substrato e do tipo de vegetação utilizada sobre o telhado, o modelo A (plantio com gramíneas) obteve um armazenamento similar a de arruamentos em terra com taxas de infiltração entre 40 e $190 \mathrm{~mm} / \mathrm{h}$ (PRUSKI et al, 1997). Em contrapartida, o modelo B (plantio com culturas herbáceas) se assemelha às condições de pastos para o mesmo grupo de solo. Devido às condições hidrológicas de cada solo e, principalmente do tipo de superfície, o volume de escoamento subsuperficial foi maior no telhado B. Solos mais expostos ou descobertos, como o proposto nesta cobertura, evidenciaram um maior acúmulo da precipitação no interior das camadas porosas do solo.

As estimativas de $C N$ podem ser aprimoradas e melhor avaliadas com base nos estudos de Gash et al (2007), que avaliaram o escoamento gerado em telhados residenciais a partir de um modelo desenvolvido para estimar a evaporação pela área do dossel de florestas. Segundo os autores o processo de evaporação do escoamento superficial em telhados residenciais é suficientemente similar ao modelo de evaporação gerado pelo dossel das florestas, portanto podem ser utilizadas para estimar o escoamento das áreas de coberturas. Tendo em vista que o presente estudo desprezou os efeitos do processo da evapotranspiração no telhado verde, é recomendado que novas avaliações sejam feitas para estimar o comportamento hidrológico de diferentes espécies no processo de interceptação junto ao balanço hídrico.

\section{CONCLUSÕES}

A aplicação do telhado verde em áreas urbanas, além de oferecer melhores condições térmicas e ambientais, retarda o escoamento superficial na drenagem. Conforme estudos realizados, áreas incorporadas por telhados verdes apresentam uma maior eficiência na sua capacidade de absorção de água pluvial em relação a um telhado convencional, com uma retenção de aproximadamente $56 \%$ do volume precipitado (para $90 \%$ de geração do escoamento em relação a precipitação total). Tais áreas de telhados verdes garantem também uma maior absorção da água pluvial no momento de maior intensidade de chuva. Isto constitui uma evidência de que telhados verdes geram o retardamento no escoamento de águas pluviais, se comparados com uma cobertura tradicional (telha). Assim, é necessário o aprimoramento desse estudo a partir dos seguintes tópicos: a) máxima taxa de infiltração da água pluvial sobre a cobertura verde, determinando conseqüentemente a máxima intensidade de chuva comportada pela mesma sem necessidade de drenos superiores para coleta do escoamento superficial; b) estudo do escoamento de água pluvial para diferentes inclinações de telhado, vide Ragab et al (2003); c) estudo da qualidade da água pluvial para determinação do seu respectivo aproveitamento; d) simulação de diversos cenários para o meio urbano com modelo Green-Ampt ou GAML (MEIN \& LARSON, 1973), considerando a intensidade e duração da chuva, assim como o total infiltrado. Sugere-se, também utilizar o telhado verde como método construtivo para residências, comércios e indústrias para comparação da redução do escoamento de água pluvial no pico de chuva e a sua influência na prevenção de enchentes e avaliação térmica dos efeitos da instalação, a partir de Lopes (2006).

\section{AGRADEGIMENTOS}

Os autores agradecem:

- ao convenio FINEP-CT-HIDRO/EESCUSP/DAEE-SP Número 01.02.0086.00 " $E x$ perimento Piloto de Gerenciamento Integrado de Bacias Urbanas para o Plano Diretor de São Carlos";

- ao Conselho Nacional de Desenvolvimento Científico e Tecnológico do Brasil, CNPq, 
quem consolidou o Grupo de Pesquisa e disponibiliza bolsa de produtividade em pesquisa;

- a Coordenação de Aperfeiçoamento de Pessoal de Nível Superior CAPES-Brasil;

- a Fundação de Amparo à Pesquisa do Estado de São Paulo, FAPESP, Processo: 03/06580-7;

- ao programa de bolsas CT-Hidro (nível Doutorado), processo $\mathrm{CNPq} \quad \mathrm{n}^{\circ}$ $142535 / 2004-4$

\section{REFERÊNCIAS}

ALMEIDA NETO, P.(2005). "Estudo hidrológico de cobertura verde leve como alternativa para controle do escoamento em lotes domiciliares". XVI Simpósio Brasileiro de Recursos Hídricos, João Pessoa, Paraíba - de 20 a 24 de novembro de 2005.

BEVEN, K. Runoff production and flood frequency in catchments of order n: an alternative approach. In: GUPTA, V; RODRÍGUEZ-ITURBE, I; WOOD, E. (ed.). Scale Problems in Hydrology. Dorbretch: Reidel, 1986. p. 107-132.

FINEP/FIPAI/DAEE-EESC (2003). "Experimento Piloto de Gerenciamento de Bacias Urbanas para o Plano Diretor de São Carlos, SP". USP. Escola de Engenharia de São Carlos www.busplanodiretor.hpg.com.br. Projeto GURH.03/2002. CTHIDRO. Convênio Finep 01.02.0086.00.

FLL (2002). Richtlinie für die Planung, Ausführung und Pflege von Dachbegrünungen. Forschungsgesellschaft Landschaftsentwicklung Landschaftsbau e.V. (FLL), Bonn. Apud: NGAN, G. (2004). Green Roof Policies: Tools for Encouraging Sustainable Design. Landscape Architect Canada Foundation.

GASH, J.H.C.; ROSIER, P.; RAGAB, R (2007). A note on estimating urban roof runoff with a forest evaporation model. In: Hydrological Process. January 2007.

KIRBY, J. R. (2005). Green Roofs: Understanding the waterproofing aspects. The Green Roof Infrastructure Monitor. North América, EUA. Vol. 1, nº 8. Acesso em 09 fev 2007. Disponível em: www.greenroofs.org.

KOCHHANN, R. A.; DENARDIN, J. E.; FAGANELLO, A. É necessária a descontinuidade do sistema plantio direto após dez anos de adoção? Comunicado Técnico Online, Empresa Brasileira de Pesquisa Agropecuária (Embrapa), n. 43, dez.
1999. Disponível em: <http://www.cnpt.embrapa.br/ biblio/p_co43.htm>. Acesso em: 07 mar. 2011.

KOLB, W. (2003). Telhados de cobertura verde e manejo de águas pluviais. Instituto Estadual de Viticultura e Horticultura do Estado de Baveria, Departamento de Paisagismo. Veitshöchheim, Alemanha.

KÖHLER, M.; SCHMIDT, M. \& SICKERMANN, J. (2003). Greened Roofs and the Technique of Water Harvesting: a Synergistic Combination. University of Applied Sciences Neubrandenburg, Germany. Gründächer und Niederschlagsretention.

LINZ (2002). Grünflächenplan der Stadt Linz 2001. Available from Magistrat der Landeshauptstadt Linz, Planungsamt.

LOPES, D. A. R. 2006. Comparação do comportamento térmico de Coberturas Verdes Leves (CVL) com coberturas tradicionais. Exame de Qualificação. Programa de Pós-Graduação em Ciências da Engenharia Ambiental, Escola de Engenharia de São Carlos, Universidade de São Paulo. São Carlos - SP. $63 p$.

MEIN, R.G.; LARSON, C.L. Modeling infiltration during a steady rain. Water Resources Research Center, Minnesotta, v.9, n.2, p.384-394, 1973.

OHNUMA JR, A. A. (2008). Medidas não-convencionais de reservação d' água para o controle da poluição em lotes urbanos. Tese de Doutorado. Ciências da Engenharia Ambiental. Departamento de Hidráulica e Saneamento. Escola de Engenharia de São Carlos. Universidade de São Paulo. 40p.

OLIVEIRA, E.W.N; SILVA, L.P.; MARY, W. (2008) Telhados verdes em habitações de interesse social e retenção das águas pluviais para drenagem urbana sustentável. XVIII Simpósio Brasileiro de Recursos Hídricos, Campo Grande, Mato Grosso do Sul - de 22 a 26 de novembro de 2008.

PENNSTATE (2008). Pennsylvania State University. hy should we plant greenroofs? Disponível em: http://hortweb.cas.psu.edu/research/greenroofcenter/history.ht ml. Acesso em 24 mai 2008.

PRUSKI, F. F.; FERREIRA, P. A.; RAMOS, M. M.; CECON, P. R. Model to design level terraces. Journal of Irrigation and Drainage Engineering. 123:8-12. 1997.

RAGAB, R.; BROMLEY, J.; ROSIER, P.; COOPER, J. D.; GASH, J. H. C. (2003). Experimental study of water fluxes in a residential area: 1. Rainfall, roof runoff and evaporation: the effect of slope and aspect. In: Hydrological Process. 17, 24092422 (2003). 
TUCCI, C.E.M. (2001). Hidrologia Ciência e Aplicação. Associação Brasileira de Recursos Hídricos (ABRH). Editora da Universidade/UFRGS. Porto Alegre/RS, $2^{\mathrm{a}}$ ed.

WILKEN, P. S. (1978). Engenharia de drenagem superficial. São Paulo: Companhia de Tecnologia de Saneamento Ambiental, Secretaria do Meio Ambiente do Governo de São Paulo, SP, 1978.

\section{Analysis Of Water Retention In Green Roofs Through An Efficient Runoff Coefficient}

\section{ABSTRACT}

This paper presents a comparative analysis of water reservation applied to green roofs. The reference of the proposal for inclusion in urban areas is a quantitative evaluation of the superficial flow generated by the rain on the green roof by monitoring up to 65 events between the months of June 04 and July 05 - Green roof A - and between September 06 and March 07 on roof B. The methodology to calculate and the estimated water reservation by the green roof considered as zero the evaporation/transpiration due to the velocity of the flow for the analysis on small scale and event lasting less than one hour. The utilized equipment included two weather stations, a manual limnigraph and two automatic groundwater dataloggers whose functions were, respectively, to measure the amount of rain during the events and to record the water level from a pressure transduction device, temperature sensor, extended life batteries and a data collector. The results indicate an efficiency of up to $56 \%$ in the storage provided by the green roof compared to a regular roof and the former had the property of slowing the flow of water. The recommendations for future work on the subject include: simulations of green roofs that cover larger areas, at different angles of inclination and an analysis of the experiment that focuses on a good use for the rain water collected from the green coverage.

Key-words: green roof; water reservation, hydrological monitoring; efficiency. 